\title{
Comparing Changes in Knee Muscle Strength after Reconstruction of the Anterior and Posterior Cruciate Ligaments
}

\author{
SangWook Hyun'1, SoHee Kim², TaeHo Kim³ \\ 'Department of Physical Therapy, Daegu Health College Hospital, Daegu; ${ }^{2}$ Department of Physical Therapy, Daegu Dalgubeol General Welfare \\ Center, Daegu; ${ }^{3}$ Department of Physical Therapy, College of Rehabilitation Science, Daegu University, Daegu, Korea
}

Purpose: The purpose of this study was to identify changes in knee muscle strength after reconstruction of the anterior cruciate ligament (ACL) and the posterior cruciate ligament (PCL).

Methods: Thirteen subjects (males) with anterior ligament injury and ten subjects (males) with posterior ligament injury voluntarily participated in this study. Both groups were evaluated at the pre-and post-reconstruction stages using an isokinetic dynamometer. Peak torque, total work, and the hamstrings to quadriceps $(\mathrm{H} / \mathrm{Q})$ peak torque ratio were calculated at angular velocities of $60^{\circ} / \mathrm{sec}$ and $180^{\circ} /$ sec. Statistical analysis was conducted on SPSS 18.0 for Windows using t-tests to compare mean differences.

Results: At an angular velocity of $60^{\circ} / \mathrm{sec}$, both the ACL and PCL groups showed a significant increase in muscle strength in the flexors and extensors. Muscle strength in the extensors was significantly increased in the PCL group compared to the ACL group. At an angular velocity of $180^{\circ} / \mathrm{sec}$, the ACL group showed a significant increase in muscle endurance in the flexors and extensors, and the PCL group showed a significant increase in muscle endurance in the flexors. At angular velocities of $60^{\circ} / \mathrm{sec}$ and $180^{\circ} / \mathrm{sec}$, the $\mathrm{H} / \mathrm{Q}$ peak torque ratio increased in the ACL group but decreased in the PCL group. Consequently, the H/Q peak torque ratio was significantly different for the two groups.

Conclusion: The results suggest that the patients with $\mathrm{ACL}$ injury should focus on strengthening the knee extensors and that the patients with PCL injury need to strengthen the knee flexors.

Keywords: Anterior cruciate ligament, Posterior cruciate ligament, Muscle strength

\section{INTRODUCTION}

With the current increasing interest in health, the number of people directly participating in sports activities is increasing, and the incidence of injuries caused by sports activities is also increasing. ${ }^{1}$ The incidence of musculoskeletal injuries is higher than other injuries. Knee joint injuries are among the most frequent injuries caused by sports and leisure activities, ${ }^{2}$ and cruciate ligament rupture is the most typical form. ${ }^{3}$ These injuries can not only cause an increase in medical expenses but also leave sequelae, which are likely to reduce quality of life.

The interactions between the structures of ligaments, tendons, meniscus, and capsule and the dynamic muscle system produce

Received Nov 4, 2019 Revised Dec 10, 2019

Accepted Dec 10, 2019

Corresponding author SoHee Kim

E-mail tindrum5@hanmail.net functional stability of the knee joint. ${ }^{4}$ The anterior cruciate ligament (ACL) has the mechanical function of maintaining the stability of the knee joint and contains mechanoreceptors, which directly affect neuromuscular control of the knee joint. ${ }^{5}$ It also acts as a static stabilizer, preventing hyperextension of the knee joint, anterior tibial translation, and rotatory movements. In addition, it restricts varus and valgus movements in all ranges of flexion. ${ }^{6}$ The posterior cruciate ligament (PCL) primarily limits posterior tibial displacement ${ }^{7}$ and, together with the ACL, contributes to the regulation of the screw home mechanism of the knee joint. ${ }^{8}$ Like the ACL, it provides stability against varus, valgus, and external rotation. ${ }^{9}$ Hughston et al..$^{10}$ have emphasized the importance of the PCL as a critical stabilizer of the knee joint.
Copylight (@2019 The Korean Society of Physical Therapy

This is an Open Access article distribute under the terms of the Creative Commons Attribution Non-commercial License (Http:// creativecommons.org/license/by-nc/4.o.) which permits unrestricted non-commercial use, distribution, and reproduction in any medium, provided the original work is properly cited. 
Anterior cruciate ligament injuries are divided into contact injuries and noncontact injuries. About 70-80\% of ACL injuries are noncontact injuries, whereas only 20-30\% are contact injuries. ${ }^{11}$ Noncontact injuries are caused by single-foot landing, direct deceleration, and pivoting, twisting, and cutting movements without direct physical contact. ${ }^{12}$ Noncontact injuries, on the other hand, are often accompanied by injuries of the medial meniscus and medial collateral ligament which are caused by strong varus external forces. ${ }^{13}$

The PCL has two major injury mechanisms. The first occurs during posterior translation of the proximal tibial bone when the knee joint is bent. Most injuries are caused by serious impact on the antero-proximal tibia (dashboard injury) due to traffic accidents and by falling when the knee joint is bent during sports activities. ${ }^{14,15}$ The second mechanism occurs when excessive force is exerted on the PCL during forced over-flexion or extension of the knee joint. ${ }^{16,17}$

Cruciate ligament injuries cause various problems in the knee joint and its periphery. Anterior cruciate ligament injury may lead to knee joint pain, instability, and secondary osteoarthritis of the knee. It can also cause serious impairments, such as muscle weakness and muscular atrophy, of the femoral muscle group. ${ }^{18-21}$ Shim and $\mathrm{Choi}^{22}$ stated that ACL injury causes a defect of proprioception. Like ACL injury, PCL injury causes pain, instability, degenerative changes, and functional deterioration of the knee joint. ${ }^{23}$

Depending on the degree of cruciate ligament injury, either conservative treatment or reconstruction can be performed. Limited movement without knee fixation or muscle contraction following cruciate ligament reconstruction especially results in poor outcomes for muscles around the knee area. ${ }^{24}$ Exercises for enhancing muscle strength, muscle endurance, and muscle power are needed to improve performances of daily activities and sports activities. Additionally, a rehabilitation program that incorporates various exercise speeds is needed to prevent injuries due to muscle strength imbalance.

Many previous studies have evaluated the effectiveness of accelerated rehabilitation programs and non-assistive rehabilitation protocols for a rapid return to daily life and sports activities. ${ }^{25,26}$ Most of these studies emphasize the importance of pre-operative rehabilitation exercises and early post-operative rehabilitation exercises and they are only simple muscle strength evaluation. They also have little distinction between muscle groups to strengthen according to each damage after surgery on the ACL and PCL. Therefore, directions for post-operative rehabilitation after ACL and PCL injuries are lacking. When the ACL and PCL are injured, it should be checked for which muscles are mainly affected. This is critical to setting the direction of treatment before and after surgery. These studies are insufficient.

This study aims to provide guidelines for post-operative rehabilitation by comparing and analyzing changes in muscle strength of the extensors and flexors of the knee joint before and after surgery in patients who have undergone reconstructive surgery due to an ACL or PCL rupture.

\section{METHODS}

\section{Subjects}

Twenty-three adult males who underwent cruciate ligament reconstruction at K general hospital in Daegu, Republic of Korea due to a rupture of the cruciate ligament of the knee joint were enrolled in this study. Group 1 is composed of 13 patients with an ACL rupture and Group 2 is composed of 10 patients with a PCL rupture. For the inclusion in the study, a patient had to meet the following criteria: unilateral ACL or PCL rupture, no previous ipsilateral and/or contralateral knee surgery, and no concurrent ligament damages that can affect the stability of knee joints except for meniscal injuries. Those who had not participated in any specialized post-operative rehabilitation program were selected as study subjects. All subjects signed a consent form to voluntarily participate in the study before the test was performed. The physical characteristics of these patients are given in Table 1.

\section{Experimental procedures}

The experimental design of this study was two groups pre and post-

Table 1. Physical characteristics of the study subjects

\begin{tabular}{|c|c|c|c|c|c|}
\hline Group & $N$ & Age (year) & Height (cm) & Weight (kg) & Period (week) \\
\hline $\mathrm{ACL}$ & 13 & $40.46 \pm 11.93$ & $170.08 \pm 7.14$ & $71.08 \pm 9.60$ & $12.62 \pm 0.96$ \\
\hline$P C L$ & 10 & $29.60 \pm 10.88$ & $176.00 \pm 5.14$ & $72.30 \pm 10.01$ & $12.40 \pm 1.58$ \\
\hline
\end{tabular}

Mean \pm SD

ACL: anterior cruciate ligament, PCL: posterior cruciate ligament, $\mathrm{N}$ : number of subjects, Period: between pre and post-test. 
test design. The experiment was divided into pre-operative (the day before surgery) and post-operative (after 12 weeks) measurements. The measurements were performed on the isokinetic dynamometer in a seated position with the back fully supported and the hip in $110^{\circ}$ of flexion using Velcro straps to stabilize the trunk, waist and the thigh of the tested leg. The contralateral leg was not strapped. The resistance pad was placed $3 \mathrm{~cm}$ above the ankle joint, and the rotation axis of the dynamometer and the knee joint were aligned to the same direction. The measurement was aborted if the patient felt uncomfortable or complained of pain during the test.

\section{Instrument}

A Biodex System 3 isokinetic dynamometer (Biodex Medical Systems, Inc., New York, USA) was used to evaluate muscle strength and muscle endurance (Figure 1).

The measurements were taken before and after surgery. Each subject rode a stationary bicycle for 10 minutes as a warm-up exer-

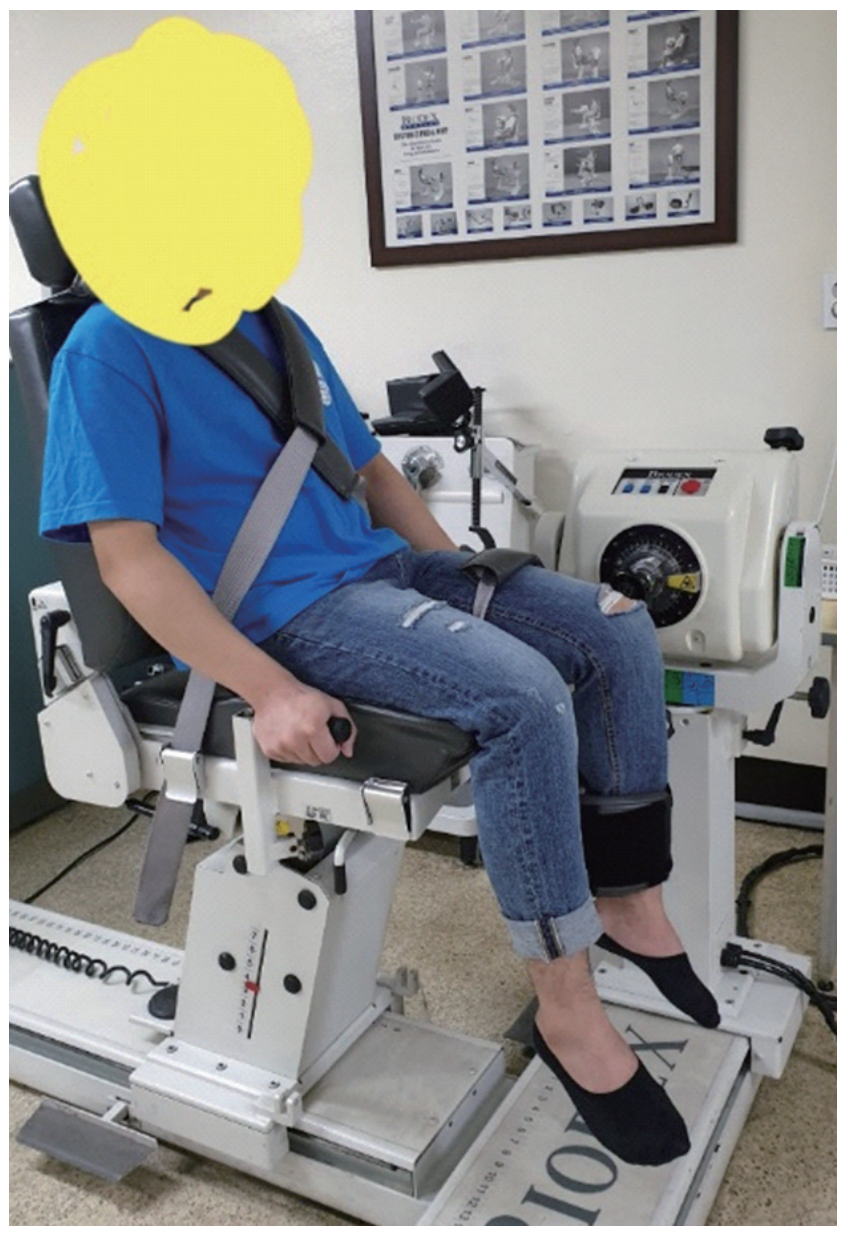

Figure 1. Isokinetic dynamometer cise before the measurement and then stretched the quadriceps and the hamstring muscle for 5 minutes. For all subjects, motion ranged from $0^{\circ}$ to $90^{\circ}$ of knee flexion. Before the measurements were taken, the subjects practiced a submaximal exercise of the knee extensors and flexors four times (angular velocities of $60^{\circ}$ and $180^{\circ} / \mathrm{sec}$ ). Then, the experimental procedure was performed five times at $60 \% \mathrm{sec}$ and ten times at $180 \%$ sec with a 1 -minute rest time between angular velocity measurements.

\section{Measurement items}

Muscle strength was evaluated at angular velocities of $60 \% \mathrm{sec}$ and $180 \%$ sec. Three items were measured: peak torque, total work, and hamstring to quadriceps peak torque ratio (H/Q peak torque ratio).

\section{Data processing}

The statistical program SPSS version 18.0 for Windows was used to calculate the means and the standard deviations of all data. The Shapiro-Wilk test was used for a test of normality. The statistical significance of the data was determined by performing an independent $\mathrm{t}$ test to compare the difference between the two groups, and a paired ttest to compare the within-group difference between before and after surgery. The significance level of the statistical tests was set at $\mathrm{p}<0.05$.

\section{RESULTS}

\section{Change in muscle strength at an angular velocity of $60 \% \mathrm{sec}$} 1) Muscle strength of extensors

At an angular velocity of $60 \% \mathrm{sec}$, the extensors of the ACL injury group showed a significant increase in total work after surgery compared to before surgery, while the extensors of the PCL injury group showed a significant increase in peak torque and total work after surgery compared to before surgery (Table 2) $(\mathrm{p}<0.05)$.

A post-operative comparison of the two groups showed that both peak torque and total work in the PCL injury group were significantly higher than in the ACL injury group (Table 2$)(\mathrm{p}<0.05)$.

\section{2) Muscle strength of flexors}

At an angular velocity of $60 \% \mathrm{sec}$, the flexors of the ACL injury group showed a significant increase in peak torque and total work after surgery compared to before surgery, while the flexors of the PCL injury group showed a significant increase in peak torque after 
Table 2. Change in muscle strength at an angular velocity of $60^{\circ} / \mathrm{sec}$

\begin{tabular}{|c|c|c|c|c|c|c|}
\hline & \multirow{2}{*}{ Variable } & \multirow{2}{*}{ Group } & \multirow{2}{*}{ Pre } & \multirow{2}{*}{ Post } & Within group & \multirow{2}{*}{$\frac{\text { Between group }}{\mathrm{p}}$} \\
\hline & & & & & $p$ & \\
\hline \multirow[t]{4}{*}{ Knee extension } & Peak torque (ft-lbs) & $\mathrm{ACL}$ & $74.95 \pm 37.07$ & $90.69 \pm 27.91$ & 0.115 & $0.003^{*}$ \\
\hline & & PCL & $99.61 \pm 34.88$ & $133.85 \pm 34.62$ & $0.009^{*}$ & \\
\hline & Total work (ft-lbs) & $\mathrm{ACL}$ & $421.63 \pm 209.46$ & $517.17 \pm 190.01$ & $0.019^{*}$ & $0.005^{*}$ \\
\hline & & $\mathrm{PCL}$ & $514.69 \pm 227.22$ & $779.84 \pm 206.09$ & $0.013^{*}$ & \\
\hline \multirow[t]{4}{*}{ Knee flexion } & Peak torque (ft-lbs) & $\mathrm{ACL}$ & $43.12 \pm 21.55$ & $56.73 \pm 21.54$ & $0.005^{*}$ & 0.474 \\
\hline & & PCL & $46.68 \pm 18.68$ & $63.09 \pm 19.56$ & $0.033^{*}$ & \\
\hline & Total work (ft-lbs) & $\mathrm{ACL}$ & $224.47 \pm 124.96$ & $329.96 \pm 138.42$ & $0.000^{*}$ & 0.916 \\
\hline & & $P C L$ & $230.34 \pm 126.51$ & $336.04 \pm 131.26$ & 0.067 & \\
\hline H/Q peak torque & & $\mathrm{ACL}$ & $54.04 \pm 11.05$ & $63.32 \pm 17.15$ & 0.116 & $0.013^{*}$ \\
\hline Ratio (\%) & & PCL & $49.62 \pm 19.61$ & $46.84 \pm 9.42$ & 0.648 & \\
\hline
\end{tabular}

Mean \pm SD, ${ }^{*} p<0.05$

ACL: anterior cruciate ligament, PCL: posterior cruciate ligament, H/Q: hamstring to quadriceps, Pre: pre-test, Post: post-test.

Table 3. Change in muscle strength at an angular velocity of $180^{\circ} / \mathrm{sec}$

\begin{tabular}{|c|c|c|c|c|c|c|}
\hline & \multirow{2}{*}{ Variable } & \multirow{2}{*}{ Group } & \multirow{2}{*}{ Pre } & \multirow{2}{*}{ Post } & \multirow{2}{*}{$\begin{array}{c}\text { Within group } \\
p\end{array}$} & \multirow{2}{*}{$\frac{\text { Between group }}{\mathrm{p}}$} \\
\hline & & & & & & \\
\hline \multirow[t]{4}{*}{ Knee extension } & Peak torque (ft-lbs) & $\mathrm{ACL}$ & $57.78 \pm 24.46$ & $70.67 \pm 22.23$ & $0.012^{*}$ & 0.149 \\
\hline & & $\mathrm{PCL}$ & $78.94 \pm 18.38$ & $86.93 \pm 29.93$ & 0.334 & \\
\hline & Total work (ft-lbs) & $\mathrm{ACL}$ & $653.49 \pm 358.33$ & $814.16 \pm 320.83$ & $0.023^{*}$ & $0.031^{*}$ \\
\hline & & $P C L$ & $883.68 \pm 385.17$ & $1097.25 \pm 246.15$ & 0.187 & \\
\hline \multirow[t]{4}{*}{ Knee flexion } & Peak torque (ft-lbs) & $\mathrm{ACL}$ & $35.56 \pm 16.72$ & $44.74 \pm 13.92$ & $0.012^{*}$ & 0.716 \\
\hline & & $\mathrm{PCL}$ & $38.33 \pm 14.35$ & $47.04 \pm 15.94$ & $0.003^{*}$ & \\
\hline & Total work (ft-lbs) & $\mathrm{ACL}$ & $315.87 \pm 208.27$ & $483.13 \pm 220.16$ & $0.001^{*}$ & 1.000 \\
\hline & & $P C L$ & $376.23 \pm 250.34$ & $483.08 \pm 198.57$ & 0.067 & \\
\hline H/Q peak torque & & $\mathrm{ACL}$ & $65.35 \pm 21.78$ & $65.42 \pm 17.11$ & 0.989 & $0.017^{\star}$ \\
\hline Ratio (\%) & & $\mathrm{PCL}$ & $50.46 \pm 11.75$ & $49.70 \pm 9.75$ & 0.812 & \\
\hline
\end{tabular}

Mean \pm SD, ${ }^{*} p<0.05$

ACL: anterior cruciate ligament, PCL: posterior cruciate ligament, H/Q: hamstring to quadriceps, Pre: pre-test, Post: post-test.

surgery compared to before surgery (Table 2$)(\mathrm{p}<0.05)$.

A post-operative comparison of the two groups showed no significant inter-group difference in peak torque and total work (Table $2)(p>0.05)$.

\section{3) Hamstring to quadriceps peak torque ratio ( $\mathrm{H} / \mathrm{Q}$ ratio)}

At an angular velocity of $60 \% \mathrm{sec}$, there was no significant withingroup difference in the H/Q ratio for either group (Table 2) (p $>0.05$ ). An inter-group comparison showed a significant difference between the two groups, the H/Q ratio increased in the ACL injury group but decreased in the PCL injury group (Table 2$)(\mathrm{p}<0.05)$.

\section{Change in muscle strength at an angular velocity of $180 \% \mathrm{sec}$}

\section{1) Muscle strength of extensors}

At an angular velocity of $180 \%$ sec, the extensors of the ACL injury group showed a significant increase in peak torque and total work after surgery compared to before surgery (Table 3) $(\mathrm{p}<0.05)$.

A post-operative comparison of the two groups showed that total work in the PCL injury group was significantly higher than that in the ACL injury group (Table 3$)(\mathrm{p}<0.05)$.

\section{2) Muscle strength of flexors}

At an angular velocity of $180 \% \mathrm{sec}$, the flexors of the ACL injury group showed a significant increase in peak torque and total work after surgery compared to before surgery, while the flexors of the PCL injury group showed a significant increase in peak torque after surgery compared to before surgery (Table 3$)(\mathrm{p}<0.05)$.

A post-operative comparison of the two groups showed no significant inter-group difference in peak torque and total work (Table 3) $(\mathrm{p}>0.05)$. 


\section{3) Hamstring to quadriceps peak torque ratio ( $\mathrm{H} / \mathrm{Q}$ ratio)}

At an angular velocity of $180 \% \mathrm{sec}$, there was no significant withingroup difference in the H/Q ratio for either group (Table 3) $(\mathrm{p}>0.05)$. A post-operative inter-group comparison showed a significant difference between the two groups, the H/Q ratio increased in the ACL injury group but decreased in the PCL injury group (Table 3$)(\mathrm{p}<0.05)$.

\section{DISCUSSION}

The purpose of this study was to comparatively analyze changes in isokinetic muscle strength of the knee joint before and after surgery in 13 adults who had undergone reconstruction due to ACL injury and 10 adults who had undergone reconstruction due to PCL injury, and, thereby, to provide guidelines for post-operative rehabilitation.

At an angular velocity of $60 \% \mathrm{sec}$, the muscle strength of the extensors and flexors of the ACL and PCL injury groups was significantly increased after surgery compared to before surgery. After surgery, the muscle strength of the extensors of the PCL injury group was significantly higher than that of the ACL injury group.

Clinically, the quadriceps femoris muscle is commonly referred to as the antagonistic muscle of the ACL, and the contractile force of the quadriceps femoris muscle causes most of the anterior cruciate ligament fibers to significantly extend. A previous study reported a $4.4 \%$ change in the ACL after maximal isometric exercise of the quadriceps femoris muscle at a 15 -degree flexion. ${ }^{27}$ This increase resulted from strong contraction of the quadriceps femoris muscle, and it was reported that maximizing the angle of repose of the knee tendon relative to the tibia while the knee joint is fully extended, also maximizes the impact on the ACL. ${ }^{28}$ The greater this angle of repose, the greater the proportion of the quadriceps femoris muscle causing anterior tibial translation relative to the femur. The hamstring muscle, on the other hand, is referred to as the antagonistic muscle of the PCL and is actively involved in the backward sliding of the tibial bone against the femur during active bending of the knee. In other words, the knee flexor is attached to the back of the tibia, which reduces the anterior tibial translation and can be applied to pull the lower leg back. ${ }^{29}$ Most PCL fibers increase in length by about $30 \%$ at a 90 -degree flexion in the full extension state, which is about a $3 \%$ increase for every 10 degrees of flexion. ${ }^{30}$ The PCL gradually increases in tension as the degree of knee flexion increases and reaches its highest tension during flexion at 90-120 de- grees, while its tension becomes relatively loose between the full extension state and flexion at 30-40 degrees..$^{31,32}$

The significant difference in the extensor muscle strength of the PCL injury group observed in the inter-group comparison of this study can be explained by the fact that the impact on the ACL of the increase in tension of the PCL due to the contraction of the quadriceps femoris muscle during extension of the knee joint is smaller than that of the tension of the ACL due to the contraction of the hamstring during flexion of the knee joint, as reported in previous studies. In addition, psychological anxiety caused by pain and joint instability seems to have contributed to this difference, considering the fact that the post-operative measurement period, at about 12 weeks, was short. Petrie and Harner ${ }^{33}$ argued that the posterolateral structures of the knee joint help to prevent posterior tibial displacement of the PCL. Therefore, it is believed that there was no difference in flexor muscle strength between the two groups.

At an angular velocity of $180^{\circ}$ 'sec, muscle endurance of the extensors and flexors of the ACL injury group was significantly increased after surgery compared to before surgery but was significantly increased only in the flexors of the PCL injury group, and there was no difference in muscle endurance in the extensors and flexors between the two groups. Lee ${ }^{3}$ evaluated isokinetic function after PCL reconstruction and found a significant difference in the muscle endurance of the flexors but no significant difference in that of the extensors between pre and post-surgery. $\mathrm{Kim}^{34}$ showed that after PCL reconstruction, muscle endurance of the extensors decreased during the first three months, and then significantly increased during the next 4-12 months, while muscle endurance of the flexors, which was measured every 3 months after reconstruction, significantly increased during the period up to 12 months. Margheritini et al. ${ }^{35}$ reported that PCL reconstruction requires a longer rehabilitation period than ACL reconstruction. Based on the findings of these previous studies, it is believed that the recovery of muscle endurance of the extensors is slower because the PCL is twice as large as the ACL, has significant tensile strength, and prevents posterior tibial displacement. Bin et al.$^{36}$ reported that weakening of the quadriceps femoris muscle tended to be more severe than that of the hamstring in the lesions located within the knee joint. The absence of an inter-group difference can be explained by the fact that the movements of the extensors and flexors became smoother after surgery and that the muscle condition did not prog- 
ress to atrophy of type II (fast-twitch fibers) fibers within the muscles, as a result, there was no significant effect on muscle endurance.

At angular velocities of $60 \% \mathrm{sec}$ and $180^{\circ} / \mathrm{sec}$, neither group showed a significant within-group difference in $\mathrm{H} / \mathrm{Q}$ peak torque ratio. However, while the inter-group comparison revealed a significant difference between the two groups, the H/Q peak torque ratio increased in the ACL injury group but decreased in the PCL injury group. The H/Q peak torque ratio of healthy knee joints generally ranges from $50 \%$ to $80 \%$ depending on the knee joint angle and the angular velocity. ${ }^{37}$ It has been reported that a H/Q peak torque ratio of $60 \%$ or higher is desirable for rehabilitation. An increase in H/Q peak torque ratio indicates that the muscle strength of the hamstring muscle has become greater than that of the quadriceps femoris muscle. Therefore, the ACL injury group had greater muscle strength of the hamstring, while the PCL injury group had weaker muscle strength of the hamstring.

This means that ACL injury requires rehabilitation measures that mainly enhance the muscle strength and muscle endurance of the extensors, while PCL injury requires rehabilitation measures that mainly enhance the muscle strength and muscle endurance of the flexors. However, strengthening of the flexors is also important after ACL injury to prevent excessive stress on the ACL. ${ }^{38}$ In practical terms, for ACL injury, it would be helpful to strengthen the flexors prior to strengthening the extensors, while for PCL injury it would be helpful to strengthen the extensors first to stabilize the knee joint and thus reduce anxiety.

Based on the above results, for ACL injury, rehabilitation for enhancing the muscle strength and muscle endurance of the flexors is recommended, while for PCL injury, rehabilitation for enhancing the muscle strength and muscle endurance of the extensors is recommended. Ensuring rapid recovery of femoral muscle strength through proper rehabilitation exercises appropriate to the type of cruciate ligament injury is considered effective for stabilizing the knee joint.

This study has some limitations. Differences in the degree of pain experienced or the degree of recovery of the subjects were not considered. Furthermore, it was difficult to exclude errors due to psychological concerns about re-injury, although endeavors were made to induce the maximum effort from the subjects during measurement. In addition, the subject's personal activities were not controlled. This study focused on muscle strength changes and did not evaluate func- tional changes of the knee joint. It is believed that changes in the knee joint functional level will be necessary in the future.

Given these results, more systematic and effective methods of measuring muscle strength and more research are needed in the future to provide stability of the knee joint, prevent re-injury, and apply appropriate rehabilitation exercise programs to the clinical setting.

\section{REFERENCES}

1. Kim DK. The effect of pre-operative exercise training program on laxity and proprioception and knee strength after ACL reconstruction. Sungkyunkwan University. Dissertation of Doctorate Degree. 2008.

2. Park JT. Effects of the application pre-operative rehabilitation program on isokinetic muscle strength and functional performance after ACL reconstruction. Korea University. Dissertation of Master's Degree. 2018.

3. Lee SJ. Effects of accelerated rehabilitation exercise on femoral muscle strength and dynamic balance stability in patients after ACL and PCL reconstruction. Kunsan National University. Dissertation of Doctorate Degree. 2018.

4. Machado F, Debieux P, Kaleka CC et al. Knee isokinetic performance following anterior cruciate ligament reconstruction: patellar tendon versus hamstrings graft. Phys Sportsmed. 2018;46(1):30-5.

5. van Melick N, van Cingel RE, Brooijmans F et al. Evidence-based clinical practice update: practice guidelines for anterior cruciate ligament rehabilitation based on a systematic review and multidisciplinary consensus. Br J Sports Med. 2016;50(24):1506-15.

6. Acevedo RJ, Rivera-Vega A, Miranda G et al. Anterior cruciate ligament injury: identification of risk factors and prevention strategies. Curr Sports Med Rep. 2014;13(3):186-91.

7. Wind WM Jr, Bergfeld JA, Parker RD. Evaluation and treatment of posterior cruciate ligament injuries: revisited. Am J Sports Med. 2004;32(7): 1765-75.

8. Fukubayashi T, Torzilli PA, Sherman MF et al. An in vitro biomechanical evaluation of anterior-posterior motion of the knee. Tibial displacement, rotation, and torque. J Bone Joint Surg Am. 1982;64(2):258-64.

9. Harner CD, Xerogeanes JW, Livesay GA et al. The human posterior cruciate ligament complex: an interdisciplinary study. Ligament morphology and biomechanical evaluation. Am J Sports Med. 1995;23(6):736-45.

10. Hughston JC, Andrews JR, Cross MJ et al. Classification of knee ligament instabilities. Part I. The medial compartment and cruciate ligaments. J Bone Joint Surg Am. 1976;58(2):159-72.

11. Boden BP, Sheehan FT, Torg JS et al. Noncontact anterior cruciate ligament injuries: mechanisms and risk factors. J Am Acad Orthop Surg. 2010;18(9):520-7.

12. Olsen OE, Mtklebust G, Engerbretsen L et al. Injury mechanisms for anterior cruciate ligament injuries in team handball: a systematic video analysis. Am J Sports Med. 2004;32(4):1002-12.

13. Boden BP, Dean GS, Feagin JA et al. Mechanisms of anterior cruciate ligament injury. Orthopedics. 2000;23(6):573-8.

14. Schulz MS, Russe K, Weiler A et al. Epidemiology of posterior cruciate ligament injuries. Arch Orthop Trauma Surg. 2003;123(4):186-91. 
15. McAllister DR, Petrigliano FA. Diagnosis and treatment of posterior cruciate ligament injuries. Curr Sports Med Rep. 2007;6(5):293-9.

16. Fowler PJ, Messieh SS. Isolated posterior cruciate ligament injuries in athletes. Am J Sports Med. 1987;15(6):553-7.

17. Kannus P, Bergfeld J, Järvinen $\mathrm{M}$ et al. Injuries to the posterior cruciate ligament of the knee. Sports Med. 1991;12(2):110-31.

18. Beynnon BD, Johnson RJ, Abate JA et al. Treatment of anterior cruciate ligament injuries, part 2. Am J Sports Med. 2005;33(11):1751-67.

19. Beynnon BD, Johnson RJ, Abate JA et al. Treatment of anterior cruciate ligament injuries, part I. Am J Sports Med. 2005;33(10):1579-602.

20. Grindem H, Snyder-Mackler L, Moksnes H et al. Simple decision rules can reduce reinjury risk by $84 \%$ after ACL reconstruction: the DelawareOslo ACL cohort study. Br J Sports Med. 2016;50(13):804-8.

21. Huber R, Viecelli C, Bizzini M et al. Knee extensor and flexor strength before and after anterior cruciate ligament reconstruction in a large sample of patients: influence of graft type. Phys Sportsmed. 2019;47(1): $85-90$.

22. Shim JK, Choi HS. Effects of sensorimotor training volume om recovery of knee joint stability in patients following anterior cruciate ligament reconstruction. J Kor Phys Ther. 2016;28(1):27-32.

23. Janousek AT, Jones DG, Clatworthy M et al. Posterior cruciate ligament injuries of the knee joint. Sports Med. 1999;28(6):429-41.

24. Beynnon BD, Johnson RJ. Anterior cruciate ligament injury rehabilitation in athletes. Biomechanical considerations. Sports Med. 1996;22(1): 54-64.

25. Schüttler KF, Ziring E, Ruchholtz S et al. Posterior cruciate ligament injuries. Unfallchirurg. 2017;120(1):55-68.

26. Senese M, Greenberg E, Todd Lawrence J et al. Rehabilitation following isolated posterior cruciate ligament reconstruction: a literature review of published protocols. Int J Sports Phys Ther. 2018;13(4):737-51.

27. Best R, Begg R. A method for calculating the probability of tripping while walking. J Biomech. 2008;41(5):1147-51.

28. Simonsen EB, Dyhre-Poulsen P, Voigt M et al. Bone-on-bone forces during loaded and unloaded walking. Acta Anat (Basel). 1995;152(2): $133-42$.

29. Lim HW. Evidence-based physical therapy for anterior cruciate ligament injury: literature review. J Kor Phys Ther 2019:31(4):161-168.

30. Waters RL, Mulroy S. The energy expenditure of normal and pathologic gait. Gait Posture. 1999;9(3):207-31.

31. Cromwell RL, Aadland-Monahan TK, Nelson AT et al. Sagittal plane analysis of head, neck, and trunk kinematics and electromyographic activity during locomotion. J Orthop Sports Phys Ther. 2001;31(5):255-62.

32. Ortega JD, Farley CT. Minimizing center of mass vertical movement increases metabolic cost in walking. J Appl Physiol. 2005;99(6):2099-107.

33. Petrie RS, Harner CD. Evaluation and management of the posterior cruciate injured knee. Operative Techniques in Sports Medicine. 1999;7(3): 93-103.

34. Kim HM. Comparison of functional recovery after rehabilitation exercise between isolated PCL and combined PLC reconstruction. Dankook University. Dissertation of Master's Degree. 2016.

35. Margheritini F, Rihn J, Musahl V et al. Posterior cruciate ligament injuries in the athlete: an anatomical, biomechanical and clinical review. Sports Med. 2002;32(6):393-408.

36. Bin SI, Cho WS, Moon HS et al. Cybex evaluation of muscle strength following arthroscopic anterior cruciate ligament reconstruction. J Korean Orthop Assoc. 1995;30(2):262-8.

37. Andrade Mdos S, De Lira CA, Koffes Fde C et al. Isokinetic hamstringsto-quadriceps peak torque ratio: the influence of sport modality, gender, and angular velocity. J Sports Sci. 2012;30(6):547-53.

38. Huegel M, Indelicato PA. Trends in rehabilitation following anterior cruciate ligament reconstruction. Clin Sports Med. 1988;7(4):801-11. 